\title{
Aortic thrombus in patients with severe COVID-19: review of three cases
}

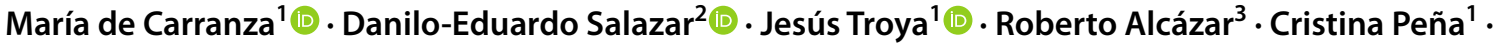 \\ Esther Aragón ${ }^{4} \cdot$ Marta Domínguez $^{5} \cdot$ Juan Torres $^{1} \cdot$ Nuria Muñoz-Rivas $^{1}$ (i)
}

Published online: 9 July 2020

(c) Springer Science+Business Media, LLC, part of Springer Nature 2020

\begin{abstract}
Coronavirus disease 2019 (COVID-19) could predispose to both venous and arterial thromboembolism, in an exaggerated immune response to the virus, especially in severe patients. Even though aortic clots are a rare entity, the pro-coagulant nature of COVID-19 is associated with thrombosis in atypical locations and should be considered in patients with severe abnormalities in coagulation parameters. We describe a series of three cases of aortic thrombi diagnosed by computerized tomography (CT) angiography in patients with confirmed SARS-CoV-2 infection.
\end{abstract}

Keywords COVID-19 $\cdot$ Aortic thrombi $\cdot$ Severe pneumonia

\section{Highlights}

- Floating aortic thrombus is an uncommon manifestation in severe SARS-CoV-2 infection.

- The incidence of aortic thrombus among arterial thrombus could probably be underestimated.

- CT angiogram may be of interest to diagnose aortic events in COVID-19 patients with no clinical improvement and high D-dimer values.

María de Carranza

mariadecarranzalopez@gmail.com

1 Department of Internal Medicine, Hospital Universitario Infanta Leonor, Infanta Leonor, University Hospital, Avenida Gran Vía Este 80, 28031 Madrid, Spain

2 Department of Radiology, Infanta Leonor University Hospital, Madrid, Spain

3 Department of Nephrology, Infanta Leonor University Hospital, Madrid, Spain

4 Department of Neurology, Infanta Leonor University Hospital, Madrid, Spain

5 Department of Cardiology, Infanta Leonor University Hospital, Madrid, Spain

\section{Introduction}

Severe acute respiratory syndrome coronavirus 2 (SARS$\mathrm{CoV}-2)$ is an unfamiliar respiratory virus that appeared in Wuhan, China in December 2019 and rapidly spread worldwide [1].

The clinical spectrum of Coronavirus disease 2019 (COVID-19) covers from asymptomatic infection to mild or severe respiratory tract affection, with potential respiratory failure and even fatal outcome [2]. The secondary involvement of many other organs with thromboembolic events has recently been reported, including central and peripheral nervous system [3], and cardiac [4, 5] or vascular systems [6-9].

Thrombotic arterial events (APE or cerebral stroke) have been previously related to other viral infections, especially among HIV patients, but no acute aortic events have been reported [10].

COVID-19 could predispose to both venous and arterial thrombotic events, especially in severe patients. An increase in the incidence of acute pulmonary thromboembolism (APE) has been recently reported in COVID-19 patients [11]. These vascular events could be associated with several factors including hyper-inflammatory processes, hypoxia, diffuse intravascular coagulation [12], and immobilization. Different anticoagulant protocols are being used, not only between institutions but also between countries, as no real 
Table 1 Main characteristics of patients with aortic trombus

\begin{tabular}{|c|c|c|c|}
\hline & Case one & Case two & Case three \\
\hline \multicolumn{4}{|l|}{ Basal characteristics } \\
\hline Age & 78 & 76 & 64 \\
\hline Sex & Male & Male & Male \\
\hline $\begin{array}{l}\text { Cardiovascular } \\
\text { Risk factors }\end{array}$ & Dyslipidemia & $\begin{array}{l}\text { Hypertension, Dyslipidemia } \\
\text { Diabetes mellitus }\end{array}$ & Former smoker, Hypertension \\
\hline Body mass index & 23.8 & 27.8 & 31.5 \\
\hline Personal history & Urothelial carcinoma & Benign prostatic hyperplasia & $\begin{array}{l}\text { Severe obstructive apnoea syndrome, } \\
\text { Chronic hepatitis B }\end{array}$ \\
\hline Ordinary treatment & Statin & $\begin{array}{l}\text { ACE2 inhibitor } \\
\text { Statin } \\
\text { Metformin } \\
\text { Protein pump inhibition }\end{array}$ & $\begin{array}{l}\text { Tenofovir } \\
\text { CPAP }\end{array}$ \\
\hline \multicolumn{4}{|l|}{ Aortic thrombus } \\
\hline Thrombus characteristics & Multiple (3), floating & Multiple (2), floating & Unique, floating \\
\hline Trombus treatment & LMWH & LMWH & Unfractioned heparin followed by LMWH \\
\hline \multicolumn{4}{|l|}{ Days to event } \\
\hline From onset of symptoms & 9 & 26 & 11 \\
\hline From admission & 5 & 9 & 7 \\
\hline \multicolumn{4}{|l|}{ Vital signs durig event } \\
\hline Blood pressure (mmhg) & $160 / 80$ & $129 / 68$ & $106 / 68$ \\
\hline Heart rate $(\mathrm{bpm})$ & 80 & 63 & 84 \\
\hline Oxygen saturation $(\%)$ & 90 & 83 & 93 \\
\hline \multicolumn{4}{|c|}{ Analytical parameters (admission—near to event) } \\
\hline Hemoglobin $(\mathrm{g} / \mathrm{l})$ & $14.2-13.6$ & $13.3-13.3$ & $14.5-13.6$ \\
\hline 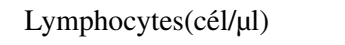 & $600-600$ & $700-2600$ & $1110-700$ \\
\hline Platelets (cél/l) & $325,000-397,000$ & $208,000-475,000$ & $169,000-363,000$ \\
\hline Inr & $1.11-1.09$ & $1.15-1.02$ & $1.02-1.05$ \\
\hline Ttpa (seg) & 27.9-20.4 & $29.4-22.3$ & $27.1-21.7$ \\
\hline Fibrinogen (mg/dl) & $>500-400$ & $>500-425$ & $>500-370$ \\
\hline $\mathrm{D}$ dimer $(\mu \mathrm{g} / \mathrm{l})$ & $910-3,570$ & $1,340-2,220$ & $670-4640$ \\
\hline Creatinine (mg/dl) & $0.86-0.90$ & $1.61-1.14$ & $0.79-0.73$ \\
\hline $\operatorname{Ldh}(\mathrm{u} / \mathrm{l})$ & $327-361$ & $364-313$ & $169-439$ \\
\hline $\operatorname{Rcp}(\mathrm{mg} / \mathrm{l})$ & $86.8-38.6$ & $133.1-4.8$ & $81.5-10.8$ \\
\hline Ferritin (ng/ml) & $1510-1272$ & NA-403 & NA-205 \\
\hline Il-6 (pg/ml) & NA-64.1 & NA-81 & NA-NA \\
\hline \multicolumn{4}{|c|}{ Covid-19: $\mathrm{x}$-ray, treatment and evolution } \\
\hline Pneumonia characteristics & Severe, bilateral & Severe, bilateral & Severe, bilateral \\
\hline Lmwh prophylaxis & $\begin{array}{l}\text { Enoxaparin } \\
\text { ( } 60 \text { mg daily) }\end{array}$ & $\begin{array}{l}\text { Enoxaparin } \\
\text { (40 mg daily) }\end{array}$ & $\begin{array}{l}\text { Enoxaparin } \\
\text { ( } 60 \mathrm{mg} \text { daily) }\end{array}$ \\
\hline Covid-19 treatment & $\begin{array}{l}\text { Piperacilin-tazobactam } \\
\text { Azitromicin } \\
\text { Hydroxicloroquine } \\
\text { Methylprednisolone } \\
\text { Tocilizumab }\end{array}$ & $\begin{array}{l}\text { Ceftriaxone } \\
\text { Azitromicin } \\
\text { Hydroxicloroquine } \\
\text { Methylprednisolone } \\
\text { Tocilizumab }\end{array}$ & $\begin{array}{l}\text { Ceftriaxone } \\
\text { Azitromicin } \\
\text { Hydroxicloroquine } \\
\text { Methylprednisolone } \\
\text { Tocilizumab }\end{array}$ \\
\hline Icu admission & No & No & Yes \\
\hline Patient evolution & Death & Middle stay center & ICU admission \\
\hline
\end{tabular}

$A C E$ angiotensin converting enzyme, $I C U$ intensive care unit, $I L-6$ Interleukin-6, $L D H$ lactate dehydrogenase, $L M W H$ low molecular weight heparin, $N A$ not available $R C P$ reactive $\mathrm{C}$ protein 
anticoagulant consensus has been defined for COVID-19 patients [13].

In our hospital, we established a specific screening protocol to rule out APE in COVID-19 patients with a significant increase of D-Dimer, even with the improvement of clinical and analytical parameters. We present three confirmedpatients for COVID-19 with floating aortic thrombi. Two of them in APE screening, and the other one in the extension study of an acute ischemic stroke. Main analytic and clinical profiles are described in Table 1.

\section{Case one}

A 78-years-old man with dyslipidemia was admitted to our Emergency Department with 4 days of fever and no other symptoms. Clinical examination was normal apart from a temperature of $37.2^{\circ} \mathrm{C}$. Laboratory tests showed lymphopenia, increased fibrinogen, LDH, and D-Dimer. Chest X-Ray (CXR) showed multilobar interstitial opacities in the right lung. At admission, we started treatment with piperacillintazobactam, azithromycin, hydroxychloroquine, methylprednisolone, and enoxaparin at a dose of $60 \mathrm{mg}$ daily. Fortyeight hours later the patient continued with persistent fever and an increase in oxygen requirements. CXR presented a rapid progression of opacities and a significant increase in acute reactants such as ferritin and IL-6 were detected, so a single dose of $600 \mathrm{mg}$ of tocilizumab was administered following hospital protocols (severity criteria). On day 5 from admission ( 9 days from the onset of the symptoms), the patient presented a clear improvement in the following $72 \mathrm{~h}$, with a decrease in C-reactive protein (CRP) and ferritin values. Despite an initial decrease, D-Dimer significantly increased to $3570 \mu \mathrm{g} / \mathrm{L}$. A CT-angiography was performed, showing multiple segmental pulmonary embolisms, multilobar pneumonia, and three floating thrombi in the aortic arch and descending aorta (Fig. 1). Low weight molecular heparin (LWMH) was started at an anticoagulant dose. We diagnosed no coagulopathy or bleeding events. The patient worsened to severe respiratory failure and died on day 18th from admission to hospital.

\section{Case two}

A 76-year-old man with hypertension, dyslipidemia, and diabetes mellitus was admitted to our emergency department with fever, asthenia, and pain in the lower back area for the last 2 weeks. Upon arrival, he presented high-temperature, 120 beats per minute, basal oxygen saturation of $87 \%$, and 22 breaths per minute. Laboratory tests showed lymphopenia and increased fibrinogen, D-Dimer, LDH, creatinine, and CRP. CXR revealed uni-lobar opacities in the lower left lobe. At admission, we started treatment with azithromycin, hydroxychloroquine, ceftriaxone, methylprednisolone, and enoxaparin $40 \mathrm{mg}$ daily. Ninety-six hours later, the patient continued with fever, dyspnea, and tachypnea, requiring high oxygen flow to increase oxygen saturation up to $92 \%$. CRP, D-dimer, ferritin, and IL-6 values increased progressively. CXR presented a worsening with the appearance of multilobar and bilateral opacities, so we increased LMWH dose to $60 \mathrm{mg}$ daily and a single dose of tocilizumab was administered, with no clinical improvement. On day 11th from admission (day 26 from the onset of the symptoms), the patient presented an abrupt episode of loss of strength in the right body with fall to the ground. The examination showed global aphasia, oculo-cephalic deviation to the left, and right faciobrachiocrural hemiplegia. The unenhanced brain CT (UBCT) showed no evidence of acute hemorrhage, mass effect, or midline shift. We started
Fig. 1 CT angiography of the pulmonary arteries. Axial and Sagittal MinIP reconstructions. Incidental finding of three floating thrombi, one immediately after the left subclavian artery bifurcation $(12.2 \mathrm{~mm})$, and two in the descending aorta immediately after the ligamentum arteriosum $(8.7 \mathrm{~mm}$ and $10.2 \mathrm{~mm}$ )

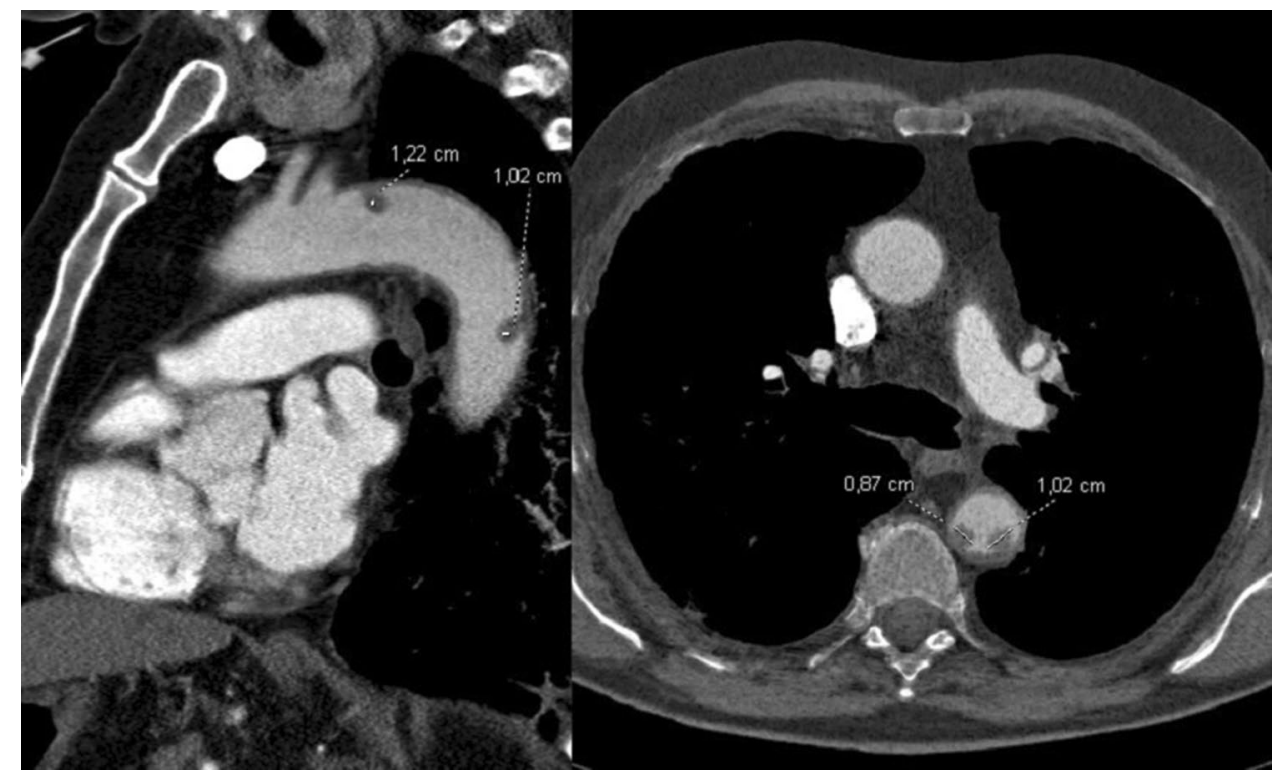



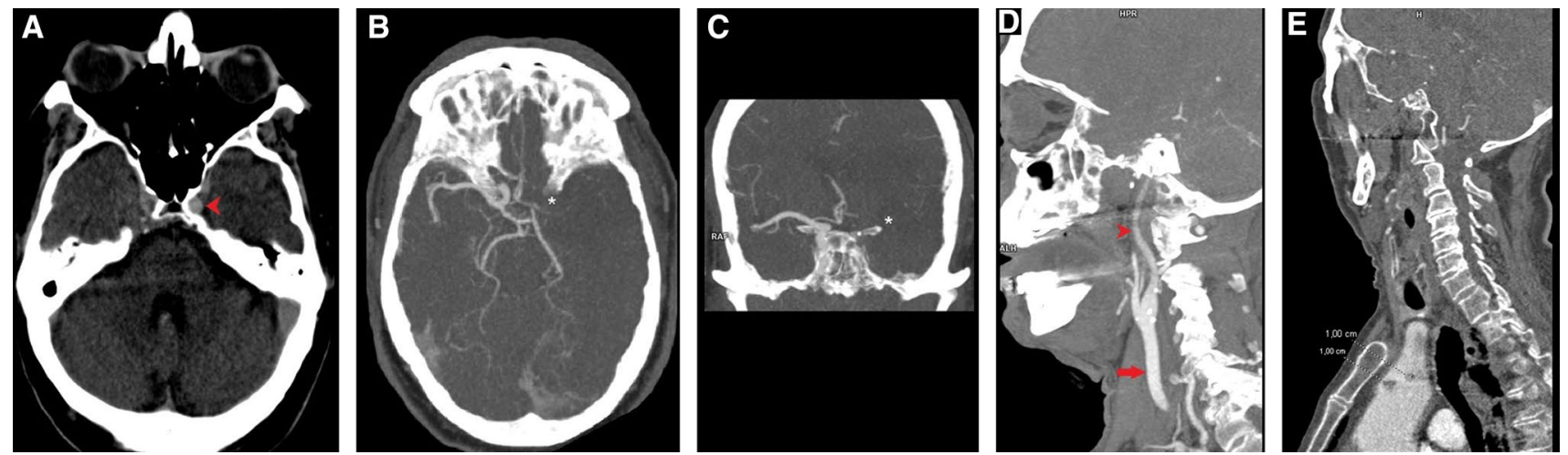

Fig. 2 a Unenhanced brain CT, showing a hyperdense intracranial left internal carotid artery in its petrous segment. $\mathbf{b}$ and $\mathbf{c} \mathrm{CT}$ angiography of the cerebral arteries (arch to vertex protocol). Axial (B) and Coronal (C) MIP reconstruction showing a complete filling defect after the petrosum segment of the left carotid artery, and an absence of the left middle cerebral artery. d CT angiography of the cerebral arteries (arch to vertex protocol). MIP reconstruction showing the left common carotid artery (red arrow) and the internal carotid artery (red arrowhead), with a prominent carotid bulb and calcified atherosclerotic plaques with no signs of lumen narrowing or wall thickening. $\mathbf{e}$ CT angiography of the carotids and cerebral arteries MIP reconstruction. Incidental finding of two floating thrombi of around $10 \mathrm{~mm}$, in the ascending aorta, just before the origin of the right brachiocephalic artery
Fig. 3 CT angiography of the pulmonary arteries. Axial and sagittal MinIP reconstructions. Incidental finding a floating thrombus in the descending aorta measuring around $12 \mathrm{~mm}$

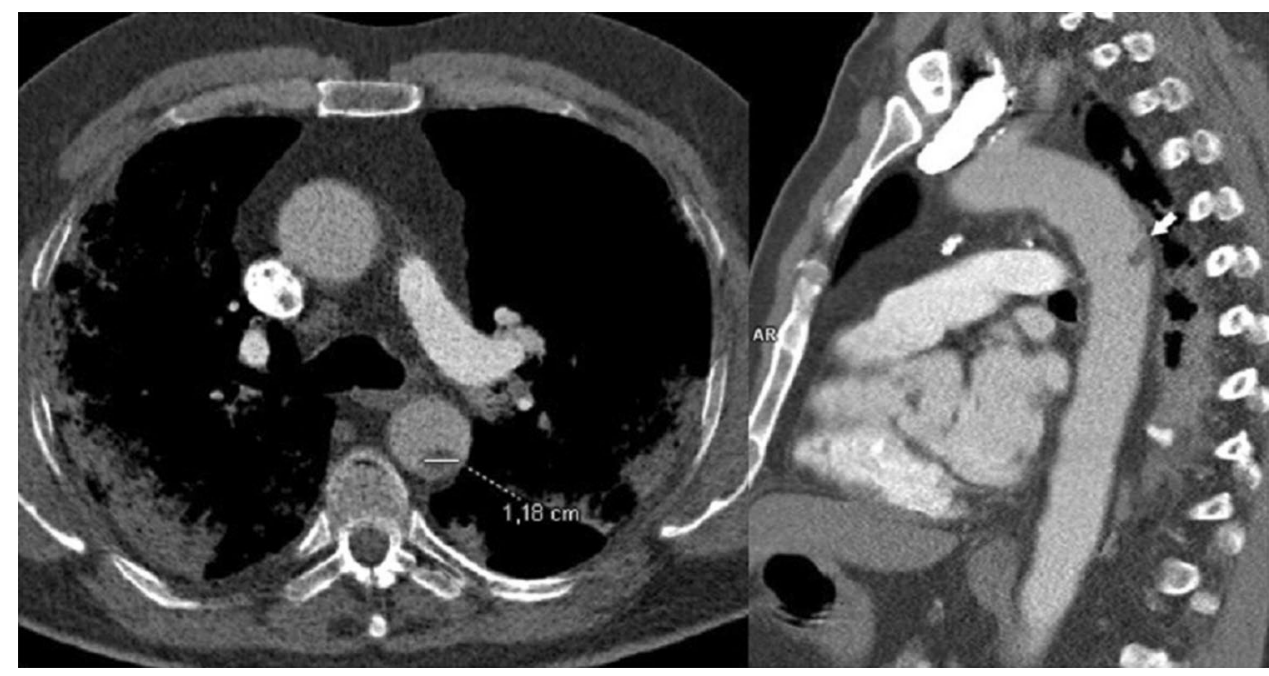

treatment with intravenous acetylsalicylic acid and reduced the dose of LMW heparin to $40 \mathrm{mg}$ daily, but no neurological improvement was observed. Forty-eight hours later a new UBCT was performed, showing signs compatible with complete ischemic stroke of the left middle cerebral artery with hyperdense vessel sign in the left intracranial internal carotid artery (Fig. 2a). We performed an angio-CT of the cerebral arteries and carotids as an extension study of ischemic stroke. It showed complete occlusion of the left internal carotid artery, incidentally, two intraluminal thrombi of $8 \mathrm{~mm}$ each were identified in the ascending aorta. We did not consider fibrinolysis or embolectomy for the hours of the evolution of the symptoms. We increased LMWH dose to anticoagulant doses, and the patient was discharged to a mid-stay center to complete rehabilitation. We intended to maintain anticoagulant treatment for at least 3 months after the event and decide in a specialized consultation after posterior reevaluation with new clinical, analytical, and imaging information unless the appearance of a major adverse event or new scientific evidence that would establish another management.

\section{Case three}

A 64-years-old man, a former smoker, with hypertension and severe obstructive sleep apnea syndrome, attended our emergency department because of dry cough, dyspnea, and a high fever for the last 4 days. Clinical examination was normal apart from a temperature of $37.3^{\circ} \mathrm{C}$. Laboratory tests showed increased fibrinogen, D-Dimer, and CRP. CXR showed unilobar interstitial opacities in the right upper lobe. We started treatment with hydroxychloroquine and azithromycin, and the 
patient was discharged $48 \mathrm{~h}$ later. During ambulatory followup, the patient presented CXR with extensive pulmonary opacities, lymphopenia, and a significant increase of CRP, and so he was re-admitted adding to the previous treatment methylprednisolone and a single dose of $600 \mathrm{mg}$ of tocilizumab (day 4 from the first visit to the emergency department). All the laboratory inflammation markers improved but D-Dimer sharply increased to $4640 \mu \mathrm{g} / \mathrm{L}$, so 7 days from admission (day 11 from the onset of symptoms), a CT to look for an APE was performed, showing a floating thrombus in the middle segment of the descending thoracic aorta (Fig. 3). We started LMWH at an anticoagulant dose. In a control of CT angiography 17 days later, we found no aortic thrombi.

\section{Discussion}

To our knowledge, floating aortic thrombus is an uncommon manifestation in SARS-CoV-2 infection [14]. We have described three moderate-severe COVID-19 patients over 60 years with cardiovascular risk factors, who presented aortic thrombus despite the use of LMWH prophylaxis, in slow and poor clinical progression with highly increased inflammatory markers. Vascular wall changes described in severe COVID-19 patients or cytokine storm, together with coagulation abnormalities could explain our findings [15].

SARS-CoV2 can directly infect endothelial cells inducing apoptosis and endothelial inflammation. These changes trigger the recruitment of macrophages and granulocytes synthesizing pro-inflammatory cytokines. If the infection is not controlled, the inflammation progresses leading to a procoagulant state, characterized by massive thrombin production [16]. The hypercoagulable state may be further enhanced by hypoxemia. Hypoxia-inducible transcription factors (HIFs) may directly activate platelets and coagulation factors, increasing TF expression, increasing PAI-1, and inhibiting the endogenous anticoagulant protein contributing to worsening hypercoagulability [17].

Likewise, the acute respiratory distress syndrome (ARDS) is a procoagulant state [18]. The diffuse pulmonary endothelial damage associated with platelet activation could predispose the formation of micro and macro thrombi, in situ, or with an embolic origin. An aortic thrombus is an uncommon condition even in common hypercoagulability states as sepsis, polycythemia, disseminated intravascular coagulation, autoimmune diseases, pregnancy, and cancer [19], and it is also an uncommon cause of peripheral arterial embolization.

Our local incidence for incidental aortic thrombus is $0.75 \%$ in moderate-severe COVID-19 patients, representing $6.6 \%$ of 45 cases of arterial thrombosis (including pulmonary embolism). This finding provides insight into pro-thrombotic changes resulting in both micro and macrovascular thrombosis [18]. Despite, COVID 19 has been recently linked to a large vessel stroke in young adults [20], the incidence of aortic thrombus among arterial thrombus could probably be underestimated, since our cases were secondarily diagnosed in CT pulmonary embolism screening. The contribution of the aortic thrombus to arterial cerebral events, as in one of our patients, and other territories embolisms remains to be determined. In some specific patients with no clinical improvement, high D-dimer values, and no other exclusion diagnosis, $\mathrm{CT}$ angiogram may be of interest to diagnose these aortic events.

Larger case series or cohort studies are necessary to confirm if this is a novel and uncommon form of thrombotic events associated with COVID-19, to identify the patient profile with this rare complication and diagnose it, because of its relevance.

Acknowledgements Infanta Leonor Thrombosis Research Group, Pilar Medrano. Patients and their families.

Author contributions MC: write and review the manuscript. Final approval. DS: Image acquisition, review the manuscript. JT: review the manuscript. RA: review the manuscript. CP: review the manuscript. EA: response to reviewers' suggestions. MD: response to reviewers' suggestions. JT: response to reviewers' suggestions. NM: write part of the discussion and review the manuscript.

Funding This study did not receive any financial support.

\section{Compliance with ethical standards}

Conflicts of interest The authors declare that they have no conflicts of interest.

\section{References}

1. World Health Organization, web-site. https://www.who.int/emerg encies/diseases/novel-coronavirus-2019. Accessed 26 Apr, 2020

2. Lai CC, Shih TP, Ko WC et al (2020) Severe acute respiratory syndrome coronavirus 2 (SARS-CoV-2) and coronavirus disease-2019 (COVID-19): the epidemic and the challenges. Int J Antimicrob Agents 55(3):105924. https://doi.org/10.1016/j.ijant imicag.2020.105924

3. Carod-Artal FJ (2020) Neurological complications of coronavirus and COVID-19. Rev Neurol 70(9):311-322. https://doi. org/10.33588/rn.7009.2020179

4. Madjid M, Safavi-Naeini P, Solomon SD, Vardeny O (2020) Potential effects of coronaviruses on the cardiovascular system: a review. JAMA Cardiol. https://doi.org/10.1001/jamacardio .2020 .1286

5. Xiong TY, Redwood S, Prendergast B, Chen M (2020) Coronaviruses and the cardiovascular system: acute and long-term implications. Eur Heart J 41(19):1798-1800. https://doi.org/10.1093/ eurheartj/ehaa231

6. Klok FA, Kruip MJHA, van der Meer NJM et al (2020) Incidence of thrombotic complications in critically ill ICU patients with COVID-19. Thromb Res S0049-3848(20):30120-30121. https:// doi.org/10.1016/j.thromres.2020.04.013 
7. Llitjos JF, Leclerc M, Chochois C et al (2020) High incidence of venous thromboembolic events in anticoagulated severe COVID19 patients. J Thromb Haemost. https://doi.org/10.1111/jth. 14869 $.10 .1111 /$ jth. 14869

8. Cui S, Chen S, Li X, Liu S, Wang F (2020) Prevalence of venous thromboembolism in patients with severe novel coronavirus pneumonia. J Thromb Haemost. https://doi.org/10.1111/jth.14830 $.10 .1111 /$ jth. 14830

9. Beun R, Kusadasi N, Sikma M, Westerink J, Huisman A (2020) Thromboembolic events and apparent heparin resistance in patients infected with SARS-CoV-2. Int J Lab Hematol. https:// doi.org/10.1111/ijlh.13230.10.1111/ijlh.13230

10. Saif MW, Greenberg B (2001) HIV and thrombosis: a review. AIDS Patient Care STDS 15(1):15-24. https://doi. org/10.1089/108729101460065

11. Lushina N, Kuo JS, Shaikh HA (2020) Pulmonary, cerebral, and renal thromboembolic disease associated with COVID-19 infection. Radiology. https://doi.org/10.1148/radiol.2020201623

12. Panigada M, Bottino N, Tagliabue P et al (2020) Hypercoagulability of COVID-19 patients in Intensive Care Unit. A report of thromboelastography findings and other parameters of hemostasis. J Thromb Haemost. https://doi.org/10.1111/jth.14850

13. Bikdeli B, Madhavan MV, Jimenez D et al (2020) COVID-19 and thrombotic or thromboembolic disease: implications for prevention, antithrombotic therapy, and follow-up. J Am Coll Cardiol S0735-1097(20):35008-35017. https://doi.org/10.1016/j. jacc.2020.04.031
14. Le Berre A, Marteau V, Emmerich J, Zins M (2020) Concomitant acute aortic thrombosis and pulmonary embolism complicating COVID-19 pneumonia. Diagn Interv Imaging. 101(5):321-322. https://doi.org/10.1016/j.diii.2020.04.003

15. Han H, Yang L, Liu R et al (2020) Prominent changes in blood coagulation of patients with SARS-CoV-2 infection. Clin Chem Lab Med. https://doi.org/10.1515/cclm-2020-0188

16. Varga Z, Flammer AJ, Steiger $P$ et al (2020) Endothelial cell infection and endothelitis in COVID-19. Lancet 395(10234):14171418. https://doi.org/10.1016/S0140-6736(20)30937-510

17. Frantzeskaki F, Armaganidis A, Orfanos SE (2017) Immunothrombosis in acute respiratory distress syndrome: cross talks between inflammation and coagulation. Respiration 93(3):212225. https://doi.org/10.1159/000453002

18. Connors JM, Levy JH (2020) Thromboinflammation and the hypercoagulability of COVID-19. J Thromb Haemost. https:// doi.org/10.1111/jth.14849.10.1111/jth.14849

19. Aksu AO, Demirkazik FB (2010) Floating aortic thrombus in a patient with non-Hodgkin's Lymphoma. Diagn Interv Radiol 16(1):63-65. https://doi.org/10.4261/1305-3825.DIR.1226-07.1

20. MacNamara D. COVID-19 Linked to Large Vessel Stroke in Young Adults. Medscape. 2020. https://www.medscape.com/ viewarticle/929345. Accessed 26 May, 2020

Publisher's Note Springer Nature remains neutral with regard to jurisdictional claims in published maps and institutional affiliations. 